\title{
On the relationship between intercategory and intracategory semantic structure
}

\author{
JAMES E. CUTTING and NANCY J. SCHATZ \\ Wesleyan University, Middletown, Connecticut 06457
}

Rosch (1975) demonstrated that intracategory semantic structure can be thought of as organized in analog rather than digital fashion. This experiment demonstrates that intercategory structure is organized along the same lines, and that it interacts with intracategory organization.

In her broad investigation of human categorization, Rosch $(1973,1975)$ demonstrated that perceptual and semantic categories can be thought of as structured in analog rather than digital fashion. That is, contrary to the usual Aristotelian conception of categories as logical, bounded groupings, internally arranged according to criterial features, Rosch proposed that categories be considered unbounded entities centered on prototypes (best examples of the category), with nonprototypic members laid out at empirically determinable distances from them. Distance from prototypes, rather than, say, the number of nodes in a semantic tree (Collins \& Quillian, 1969) has important ramifications for processing. One can decide whether two items belong to the same category much faster when both items are good examples of that category than when they are poor examples. If the items belong to different categories, goodness-ofexample also predicts decision time: The more prototypic each is of its own category, the more rapidly one can make the appropriate "different" response. These results are particularly interesting because they are not due to word-frequency effects (Mervis, Catlin, \& Rosch, 1976), but to the internal structure of categories.

Semantic categories used by Rosch (1975) include furniture, fruit, vehicles, weapons, vegetables, tools, birds, sports, toys, and clothing. These 10 , according to Rosch, virtually exhaust the population of large categories of common nouns. While she has been primarily concerned with internal structure (Rosch, 1973, 1975; Rosch \& Mervis, 1975; Mervis, Catlin, \& Rosch, 1975), we noticed that her categories seem to have their own metastructure. Specifically, fruits and vegetables both belong to the superordinate category food, while clothing, for example, does not. Following the logic of Rosch's work, we propose that if intracategory structure is of analog form, then intercategory structure should be analog as well. That is, decisions as to whether two items belong to the same category ought to be a function of both semantic distance of items from their prototypes (or prototypicality) and semantic distance between the categories themselves. Moreover, given the proposed unbounded structure of semantic memory, intracategory and intercategory organization ought to interact. More concretely, these notions predict three kinds of results:
(1) goodness-of-example, or prototypicality, should continue to yield a main effect for categorization, with better examples yielding faster decisions than poorer examples; (2) semantic proximity of prototypes ought to affect categorization decisions, with items belonging to closer categories requiring more time than those of more distant categories; and (3) goodness-of-example ought to interact with semantic proximity of prototypes, yielding very long decision times for poor examples of semantically close categories. The present experiment confirms these predictions in a card-sorting task.

\section{METHOD}

Thirty-six words were selected from Rosch (1975, Table A1), 12 from each of the categories of fruit, vegetables, and clothing. For each category four words were good examples, with prototypicality ratings on Rosch's 7-point unipolar scale averaging 1.57; four words were intermediate examples, with ratings averaging 2.75; and four were poor examples, with ratings averaging 4.55.

Nine sets of word pairs were assembled, three possible category comparisons among fruit, vegetables, and clothing, for each of the three levels of goodness. Comparisons of fruit and vegetables were treated as closely related categories, and those of fruit and clothing and of vegetables and clothing as distantly related categories. Items within each category occurred in both comparisons with the other categories. Instead of mounting the words on slides, presenting them tachistoscopically, and measuring discrete reaction time (Rosch, 1975), we typed word pairs on 6.4 by $9 \mathrm{~cm}$ white cards to be sorted. Items in the pair appeared one over the other in the center of the card, with $.6 \mathrm{~cm}$ between them. Sixteen cards were in each of nine decks. In half of all comparisons within a deck, both words were members of the same category, and in half they were members of different categories. In half of the "same" comparisons, both items belonged to one category, and in half they belonged to the other; in half of the "different" comparisons, the item of the first category appeared on top, and in half the configuration was reversed. Each word occurred four times in each deck: once on the top of a "same" pair, once on the bottom of a "same" pair, once on the top of a "different" pair, and once on the bottom of a "different" pair. Sample pairs are shown in Table 1.

Twelve Wesleyan University undergraduates, six males and six females, were paid $\$ 2$ to sort all decks. Experimental sessions began with a verbal description of the basic design. Participants were told to sort each deck into two piles, one for same pairs and one for different pairs. They were advised to work as rapidly as possible but to make few errors. Sorting times were 
Table 1

Sample Stimulus Pairs

\begin{tabular}{|c|c|c|c|c|}
\hline \multirow{2}{*}{ Categories to be Sorted } & & \multicolumn{3}{|c|}{ Level of Goodness-of-Example } \\
\hline & & High & Medium & Low \\
\hline \multirow[b]{2}{*}{ Vegetables vs. Clothing } & Same & $\begin{array}{l}\text { lettuce/pea } \\
\text { skirt/socks }\end{array}$ & $\begin{array}{l}\text { bean/peppers } \\
\text { shoe/tie }\end{array}$ & $\begin{array}{l}\text { mushroom/rice } \\
\text { purse/scarf }\end{array}$ \\
\hline & Different & $\begin{array}{l}\text { pea/pants } \\
\text { skirt/lettuce }\end{array}$ & $\begin{array}{l}\text { bean/shoe } \\
\text { tie/peppers }\end{array}$ & $\begin{array}{l}\text { rice/purse } \\
\text { purse/mushroom }\end{array}$ \\
\hline \multirow[b]{2}{*}{ Fruit vs. Clothing } & Same & $\begin{array}{l}\text { orange/apricot } \\
\text { skirt/socks }\end{array}$ & $\begin{array}{l}\text { fig/raspberry } \\
\text { shoe/tie }\end{array}$ & $\begin{array}{l}\text { prune/date } \\
\text { purse/scarf }\end{array}$ \\
\hline & Different & $\begin{array}{l}\text { orange/skirt } \\
\text { socks/melon }\end{array}$ & $\begin{array}{l}\text { fig/tie } \\
\text { shoe/raspberry }\end{array}$ & $\begin{array}{l}\text { prune/hat } \\
\text { purse/date }\end{array}$ \\
\hline \multirow{2}{*}{ Vegetables vs. Fruit } & Same & $\begin{array}{l}\text { pea/spinach } \\
\text { apricot/melon }\end{array}$ & $\begin{array}{l}\text { eggplant/bean } \\
\text { fig/raspberry }\end{array}$ & $\begin{array}{l}\text { parsley/mushroom } \\
\text { date/olive }\end{array}$ \\
\hline & Different & $\begin{array}{l}\text { pea/apricot } \\
\text { melon/artichoke }\end{array}$ & $\begin{array}{l}\text { eggplant/raspberry } \\
\text { peppers/fig }\end{array}$ & $\begin{array}{l}\text { parsley/date } \\
\text { olive/rice }\end{array}$ \\
\hline
\end{tabular}

measured by a stopwatch. Preceding every sort, participants were encouraged to thumb through the deck to familiarize themselves with the words and their lay-out on the cards. At that time they were given the superordinate category names, and the deck was reshuffled. This familiarization procedure was intended to parallel the priming technique used by Rosch (1975.)

The order of sorting category pairs varied systematically across participants. Half sorted the three vegetable/clothing decks first, the fruit/vegetable decks second, and the fruit/ clothing decks last, while the other half sorted in the reverse order. In this manner the closely related categories were sorted second, with distantly related categories sorted before and after. In our analysis of the data, we combine the two distantly related category comparisons. The three levels of goodness within a set of comparisons were sorted before moving on to the next set of comparisons. Level order was counterbalanced across participants. Three practice sorts with different decks preceded test sorts.

\section{RESULTS AND DISCUSSION}

Mean sorting times for each category comparison for each of the three levels of goodness are shown in Figure 1. The main effect of level of goodness was statistically reliable $[\mathrm{F}(2,22)=7.99, \mathrm{p}<.01]$, with means of $23.8,26.1$, and $28.9 \mathrm{sec}$. This result replicates that of Rosch (1975). As expected, the effect of semantic proximity of categories was also significant $[F(1,11)=19.06, p<.001]$, with closely related categories requiring considerably more decision time $(29.9 \mathrm{sec})$ than distantly related categories $(22.6 \mathrm{sec})$. Of primary interest, however, is the interaction between level of goodness and semantic proximity of categories, $[\mathrm{F}(2,22)=5.5, \mathrm{p}<.025]$. That is, semantic proximity differentially impedes decisions about category membership according to prototypicality, with poor examples of close categories being extremely difficult to sort. Error rates correspond to sorting times, with high, medium, and low levels of goodness yielding $3 \%, 4 \%$, and $12 \%$ errors for closely related categories, but only $2 \%, 0 \%$, and $2 \%$ errors for distantly related categories $\left[\chi^{2}(2)=13.5\right.$, $\mathrm{p}<.01]$.
These results are not surprising, especially since the distinction between fruits and vegetables is not always easy to make. Botanically the distinction is clear-cut: Fruits are ripening seeds and their adjacent tissues, while vegetables are leaves, stems, or roots. Conventionally, however, the two categories overlap. A tomato, for example, is technically a fruit but normally considered a vegetable. In the hope of avoiding overt confusion, we purposefully omitted such ambiguous items. These problems, however, speak directly to Rosch's main point: Our conceptual categories are fuzzy rather than internally regimented.

The importance of these results is that the nature of

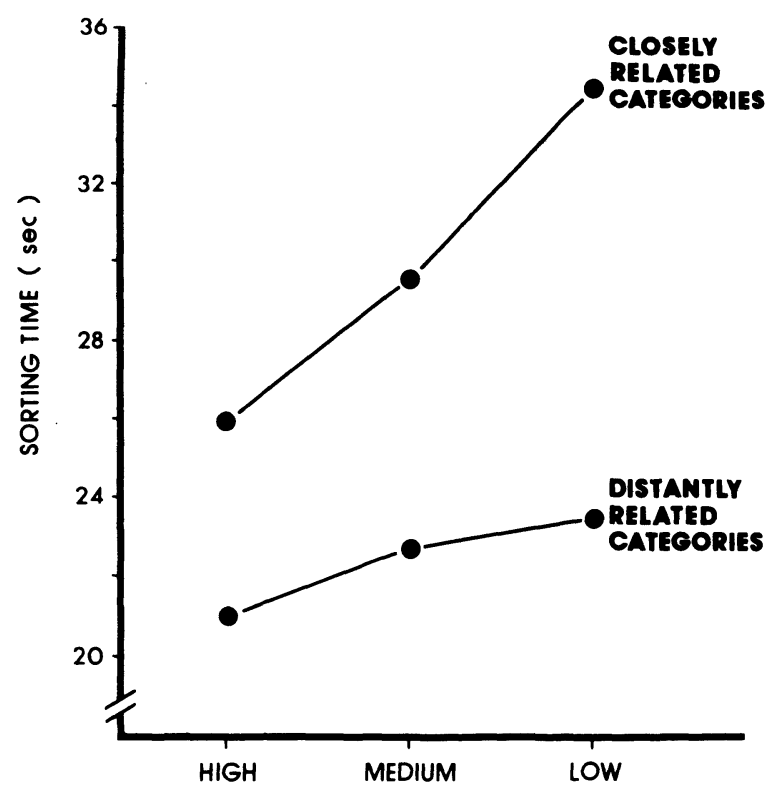

LEVEL OF GOODNESS-OF-EXAMPLE

Figure 1. Sorting times for category comparisons varied in goodness-of example and in semantic proximity. 
the structure between categories is not separable from that within categories. The interaction of goodness-ofexample with proximity of categories to each other suggests that the conceptual framework for both dimensions is woven from the same cloth. In other words, moving away from one prototype often brings one closer to prototypes of an adjoining category, and poor instances of one category possess more attributes common to other categories than do good instances (Rosch \& Mervis, 1975). While these results support the views of Rosch, they are also consistent with those of other theorists (Collins \& Loftus,1975).

\section{REFERENCES}

Collins, A. M., \& Quillian, M. R. Retrieval time from semantic memory. Journal of Verbal Learning and Verbal Behavior, 1969, 8, 240-247.
Collins, A. M., \& Loftus, E. F. A spreading-activation theory of semantic processing. Psychological Review, 1975, 82, 407-428.

Mervis, C. B., Catlin, J., \& Rosch, E. Development of the structure of color categories. Developmental Psychology, $1975,11,54-60$.

Mervis, C. B., Catlin, J., \& Rosch, E. Relationships among goodness-of-example, category norms, and word frequency. Bulletin of the Psychonomic Society, 1976, 7, 283-284.

Rosch. E. On the internal structure of perceptual and semantic categories. In T. E. Moore (Ed.), Cognitive development and the acquisition of language. New York: Academic Press, 1973.

Rosch, E. Cognitive representation of semantic categories. Journal of Experimental Psychology: General, 1975, 104, 192-233.

Rosch, E., \& Mervis, C. B. Family resemblances: Studies in the internal structure of categories. Cognitive Psychology, $1975,7,573-605$.

(Received for publication July 23, 1976.) 